\title{
HUBUNGAN FREKUENSI MINUM SOFT DRINK (BERSODA) TERHADAP PH SALIVA DAN ANGKA DMF-T PADA MAHASISWA D-IV JURUSAN KEPERAWATAN GIGI POLTEKKES MAKASSAR
}

\author{
Asriawal, Johnny Angki
}

\begin{abstract}
ABSTRAK
Minuman bersoda adalah minuman yang dikarbonasikan. Masalah penyakit infeksi gigi dan mulut yang masih sering terjadi di Indonesia salah satunya adalah karies gigi. Karies gigi dapat menyerang seluruh lapisan masyarakat dalam semua kelompok umur tanpa memandang jenis kelamin dan status sosial. Tujuan yang ingin dicapai dalam penelitian ini untuk mengetahui adanya hubungan frekuensi minum soft drink (bersoda) terhadap $\mathrm{pH}$ saliva dan angka DMF-T pada Mahasiswa D-IV Alih Jenjang Jurusan Keperawatan Gigi Poltekkes Makassar. Jenis penelitian ini adalah penelitian analitik dengan uji kolerasi persen. Populasi penelitian ini adalah seluruh Mahasiswa D-IV Alih Jenjang Jurusan Keperawatan Gigi angkatan pertama dengan jumlah 40 orang di Kampus Poltekkes Kemenkes Makassar. Sampel penelitian diambil dengan cara total sampling. Hasil penelitian ini menunjukkan bahwa nilai korelasi yang terbentuk adalah 0.855 dengan nilai Sign $0.000<0.05$ yang artinya ada hubungan antara frekuensi minum soft drink dengan pH saliva dimana ketika frekuensi minum soft drink meningkat maka nilai $\mathrm{pH}$ saliva akan menurun. Dari hasil uji kolerasi diperoleh nilai kolerasi 0.222 dengan nilai Sign $0.169>0.05$ menunjukkan korelasi yang tidak signfikaan (tidak ada hubungan) antara frekuensi minum soft drink dengan angka DMF-T dimana ketika frekuensi minum soft drink meingkat hal itu tidak berhubungan dengan angka DMF-T.
\end{abstract}

Kata Kunci: Soft Drink, $p H$ Saliva, DMF-T

\section{PENDAHULUAN}

Pengertian Kesehatan Dunia WHO pada piagam Ottawa yang didedikasikan untuk promosi kesehatan pada tahun 1986. Pada saat itu, Organisasi Kesehatan Dunia (WHO) tersebut menyatakan bahwa kesehatan bukan tujuan dari hidup melainkan sumber daya untuk hidup sehari-hari. Selain itu kesehatan diktakan juga sebagai suatu konsep yang positif dan terfokus pada kemampuan fisik. Kemudian pengertian kesehatan juga merupakan suatu keadaan atau kondisi dari jiwa dan raga sert juga sosial yang dapat menjadikan seseorang dengan kehidupannya yang produktif baik dari segi ekonomi maupun dari segi kehidupan sosialnya. (Aritonang, 2014)

Defenisi sehat sebagai keadaan keseimbangan yang dinamis dari badan dan fungsi fungsinya sebagai hasil penyesuaian yang dinamis terhadap kekuatan-kekuatan yang cenderung menggangunya. Badan seseorang bekerja secara aktif untuk mempertahankan diri agar tetap sehat sehingga kesehatan selalu harus dipertahankan. (Aritonang, 2014)

Menurut Undang-undang RI No.36 tahun 2009 tentang kesehatan, menjelaskan bahwa pelayanan kesehatan gigi dan mulut adalah upaya kesehatan dengan pendekatan pemeliharaan, peningkatan kesehatan (promotif), pencegahan penyakit (preventif), pengobatan penyakit (kuratif) dan pemulihan kesehatan (rehabilitatif). Program ini dilaksanakan secara terencana, menyeluruh, terpadu dan berkesinambungan, ditujukan pada sekelompok tertentu yang dapat diikuti dalam suatu kurun waktu tertentu, untuk mencapai tujuan "kesehatan gigi dan mulut yang optimal". (UU RI, 2009)

Masalah penyakit infeksi gigi dan mulut yang masih sering terjadi di Indonesia salah satunya adalah karies gigi. Karies gigi dapat menyerang seluruh lapisan masyarakat dalam semua kelompok umur tanpa memandang jenis kelamin dan status sosial. 
Salah satu kelompok umur yang sering mengalami masalah penyakit tersebut adalah kelompok usia sekolah dasar. Menurut data WHO (World Health Organization) (2013), terjadi peningkatan prevalensi karies gigi pada kelompok umur 12 tahun, yakni sebesar 13,7\% dari 28,9\% pada tahun 2007 naik menjadi $42,6 \%$ pada tahun 2013. Prevalensi Indek DMF-T menurut data Riskesdas (2013), adalah 1,4\%. (Jannah, 2016)

Hal ini melebihi dari target $\mathrm{WHO}$ yakni DMF-T hanya $1 \%$, sehingga dapat dikatakan bahwa Negara kita masih belum berhasil memenuhi target WHO. Menurut data Riskesdas (2013), terjadi peningkatan prevalensi karies gigi di Indonesia, yakni penderita karies gigi aktif meningkat sebesar 9,8\% dari 43,4\% pada tahun 2007 menjadi $53,2 \%$ pada tahun 2013, sedangkan penderita pengalaman karies meningkat 5,1\% dari $67,2 \%$ pada tahun 2007 naik menjadi $72,3 \%$ pada tahun 2013. Menurut kelompok umur 12 tahun juga terjadi peningkatan prevalensi karies gigi, yakni penderita karies gigi aktif meningkat $12,8 \%$ dari $29,8 \%$ pada 2 tahun 2007 menjadi 42,6\% pada tahun 2013, sedangkan penderita pengalaman karies gigi meningkat $14,1 \%$ dari $36,1 \%$ pada tahun 2007 naik menjadi 50,2\%. Penderita karies aktif adalah penderita karies yang belum ditangani atau belum dilakukan penambalan/ditumpat. Sedangkan penderita pengalaman karies adalah orang dengan riwayat/pengalaman karies dimana Decay, Missing, Filling-Teeth $>0$ (Decay merupakan Jumlah gigi karies yang tidak ditambal/yang masih dapat ditambal, Missing merupakan Jumlah gigi yang indikasi untuk dicabut/gigi yang telah hilang karena karies, Filling merupakan Jumlah gigi yang telah ditambal dan masih baik). Sebagian besar penduduk
Indonesia berumur $>10$ tahun pada tahun 2007 dan 2013 mempunyai kebiasaan menggosok gigi setiap hari dan meningkat, yakni pada tahun 2007 sebesar 91,1\% menjadi $93,8 \%$ pada tahun 2013. (Jannah, 2016)

Namun terjadi penurunan pada perilaku menggosok gigi dengan benar pada penduduk berumur >10 tahun, yakni 7,3\% pada tahun 2007 menjadi 2,3\% pada tahun 2013 (Riskesdas, 2013). Hal tersebut bisa disebabkan karena kurangnya pengetahuan dan kurangnya kesadaran penduduk Indonesia terhadap kebersihan gigi, juga adanya beberapa wilayah yang masih sulit terjangkau informasi akibat keadaan geografis yang tidak memungkinkan. (Jannah, 2016).

Rasa manis merupakan rasa yang paling disukai kebanyakan orang terutama anak-anak. Sumber rasa manis ini dapat diperoleh dari sukrosa yang dikonsumsi dalam bentuk gula dan sering digunakan untuk makanan dan minuman terutama minuman ringan. Rasa manis yang terdapat dalam minuman ringan diperoleh dari pemanis buatan. Pemanis buatan yang sering terdapat dalam minuman ringan dipasaran adalah aspartam. Aspartam memiliki rasa manis hingga 200 kali lipat dibandingkan gula, sehingga tak heran aspartam digunakan dalam produk minuman ringan. (Rahmawati dkk, 2015).

Bila kita makan gula-gula atau makanan yang manis termasuk minuman ringan, maka bakteri-bakteri dala plak akan mengubahnya menjadi asam. Asam ini akan menurunkan derajat keasaman air ludah yang kemudian akan menyebabkan terjadinya proses dekalsifikasi enamel sehingga lama kelamaan terjadilah karies gigi. (Rahmawati 
dkk, 2015)

Penurunan $\mathrm{pH}$ yang berulang-ulang dalam waktu tertentu akan mengakibatkan demineralisasi permukaan gigi secara perlahan-lahan. Untuk meningkatkan $\mathrm{pH}$ saliva dapat dengan cara minum air putih minimal 6 - 8 gelas perhari. Atau sekitar 1,5 2 liter. Kebutuhan tersebut akan meningkat pada kondisi tertentu, seperti pada cuaca yang panas, sedang beraktifitas berat, kondisi demam atau stress. Dari total kebutuhan cairan, $80 \%$ dipenuhi dari minuman sedangkan $20 \%$ sisanya dari makanan. Dalam perkembangan peradaban manusia selain mengkonsumsi "air putih" berbagai cara dilakukan untuk menambah kenikmatan dalam mengkonsumsi minuman termasuk melalui penambahan variasi rasa, warna maupun kemasan. Industri minuman modern menjadi sangat berkembang seperti aneka minuman ringan (minuman bersoda). (Nabila dkk,2016)

Minuman bersoda adalah minuman yang dikarbonasikan. Minuman bersoda memiliki rumus $\mathrm{H} 2 \mathrm{CO} 3$ yang terdiri dari komponen air, zat pewarna, kafein, glukosa, bisphenol A, dan asam sitrat. Air ludah (saliva) dan plak mempunyai $\mathrm{pH}$ 6,5. Titik kritis untuk kerusakan gigi adalah 5,7 dan ini dicapai dan terlampaui sekitar 2 menit setelah gula masuk kedalam plak. Jika gula masuk dalam makanan dan minuman telah ditelan, diperlukan sekitar 13 menit untuk menaikkan $\mathrm{pH}$ keatas titik kritis sehingga kerusakan gigi dapat terhenti. (Nabila dkk, 2016)

Istilah $\mathrm{pH}$ merupakan symbol yang digunakan untuk menunjukkan tingkat keasaman atau kebasaan suatu larutan. Semua jenis larutan mengandung ion hidrogen dan hidroksil. Semakin banyak ion hydrogen, semakin asam larutan tersebut.
Jika ion hidroksil melebihi ion hydrogen, larutan tersebut bersifat basa, namun bila jumlah kedua ion tersebut sama, larutan tersebut bersifat netral. (Aritonang, 2014)

Menurut pengamatan beberapa mahasiswa D-IV khususnyan Alih Jenjang Keperawatan Gigi pada saat jam istirahat mempunyai kebiasaan mengkonsumsi minuman soft drink. Berdasarkan hal tersebut peneliti berharap bisa melakukan penelitian agar mengetahui Hubungan Frekuensi Minum Soft Drink (Bersoda) Terhadap pH Saliva Dan Angka DMF-T Pada Mahasiswa D-IV Alih Jenjang Jurusan Keperawatan Gigi Poltekkes Makassar.

Tujuan dari penelitian ini yaitu untuk mengetahui ada hubungan frekuensi minum soft drink (bersoda) terhadap $\mathrm{pH}$ saliva dan angka DMF-T pada Mahasiswa D-IV Alih Jenjang Jurusan Keperawatan Gigi Poltekkes Makassar.

\section{METODE PENELITIAN}

Jenis penelitian ini adalah penelitian analitik dengan uji kolerasi persen suatu penelitian untuk mengetahui hubungan antara frekuensi minuman soft drink terhadap $\mathrm{pH}$ saliva dan hubungan antara frekuensi soft drink dengan angka DMF-T dengan cara pemeriksaan $\mathrm{pH}$ saliva dan angka DMF-T. peneliti ingin mengetahui hubungan frekuensi minum soft drink terhadap $\mathrm{pH}$ saliva dan angka DMF-T pada Mahasiswa D-IV Alih Jenjang Jurusan Keperawatan Gigi Poltekkes Makassar. Penelitian ini bertempat di Politeknik Kesehatan Makassar Jurusan Keperawatan Gigi. Populasi dalam penelitian ini adalah seluruh Mahasiswa D-IV Alih Jenjang Jurusan Keperawatan Gigi angkatan pertama dengan jumlah 40 orang. Sampel dalam penelitian ini diambil secara total 
sampling. Prosedur penelitian yaitu Peneliti melakukan pemeriksaan subjektif dengan wawancara pada responden guna untuk mendapatkan nilai frekuensi minum soft drik dalam seminggu. Peneliti melakukan pemeriksaan objektif atau pemeriksaan langsung pada rongga mulut responden untuk memperoleh angka DMF-T. Peneliti melalukan pengukuran $\mathrm{pH}$ saliva, dengan cara : Responden diinstruksikan untuk tidak makan dan minum 1 jam sebelum pengambilan saliva, tidak menelan dan mengunyah selama pengumpulan saliva, Responden diinstruksikan untuk duduk sambil menundukkan kepala kurang lebih $45^{\circ}$ terhadap lantai, metode pengumpulan saliva yang digunakan adalah metode Passive Drool yaitu dengan cara mulut agak dibuka kemudian saliva dibiarkan mengalir kedalam wadah saliva, apabila saliva sukar keluar dapat dibantu dengan lidah mendorong saliva masuk kedalam wadah saliva dan Pengumpulan saliva dilakukan selama 60 detik. Setelah itu $\mathrm{pH}$ saliva diukur menggunakan $\mathrm{pH}$ meter dan hasilnya dicatat.

\section{HASIL PENELITIAN}

Setelah dilakukan penelitian tentang hubungan frekuensi minum soft drink (bersoda) terhadap $\mathrm{pH}$ saliva dan angka DMFT pada mahasiswa D-IV Alih Jenjang Jurusan Keperawatan Gigi Poltekkes Makassar maka diperoleh hasil. Dimana hasil ini ditampilkan dalam bentuk tabel distribusi frekuensi sebagai berikut:

Tabel 1 Distribusi Frekuensi Sampel Berdasarkan Jenis Kelamin

\begin{tabular}{ccc}
\hline Jenis Kelamin & Frekuensi & Persentase (\%) \\
\hline Laki-laki & 6 & $15 \%$ \\
Perempuan & 34 & $85 \%$ \\
Total & 40 & $100 \%$ \\
\hline
\end{tabular}

Pada tabel 1 Diketahui jumlah sampel berjumlah 40 orang. Dimana jumlah laki-laki sebanyak $15 \%$ atau sebanyak 6 orang dan jumlah perempuan sebanyak $85 \%$ atau sebanyak 34 orang.

Tabel 2 Distribusi Frekuensi Mahasiswa Meminum Sof Drink

\begin{tabular}{ccc}
\hline $\begin{array}{c}\text { Frekuensi Minum } \\
\text { Soft Drink Dalam Seminggu }\end{array}$ & Jumlah Mahasiswa & Persentase (\%) \\
\hline $\mathbf{0}$ & 4 & $10.00 \%$ \\
$\mathbf{1}$ & 16 & $40.00 \%$ \\
$\mathbf{2}$ & 6 & $15.00 \%$ \\
$\mathbf{3}$ & 7 & $17.50 \%$ \\
$\mathbf{4}$ & 2 & $5.00 \%$ \\
$\mathbf{5}$ & 3 & $7.50 \%$ \\
$\mathbf{6}$ & 2 & $5.00 \%$ \\
Total & 40 & $100.00 \%$ \\
\hline
\end{tabular}


Berdasarkan tabel di atas dapat dilihat bahwa dari 40 orang mahasiswa yang diteliti ada 4 orang (10.00\%) yang tidak pernah meminum soft drink, 16 orang $(40.00 \%)$ yang meminum 1 kali seminggu, ada 6 orang (15.00\%) yang meminum 2 kali seminggu, 7 orang (17.50\%) yang meminum 3 kali seminggu, 2 orang (5.00\%) yeng meminum 4 kali seminggu, 3 orang $(7.50 \%)$ yang meminum 5 kali seminggu, dan 2 orang $(5.00 \%)$ yang meminum 6 kali dalam seminggu.

Tabel 3 Distribusi Frekuensi pH saliva Mahasiswa D-IV Alih Jenjang Jurusan Keperawatan Gigi Poltekkes Makassar

\begin{tabular}{ccc}
\hline $\mathbf{p H}$ & Jumlah Mahasiswa & Persentase (\%) \\
\hline $\mathbf{5}-\mathbf{5 . 6}$ & 7 & $17.50 \%$ \\
$\mathbf{6}-\mathbf{6 . 8}$ & 29 & $72.50 \%$ \\
$\mathbf{7}-\mathbf{7 . 2}$ & 4 & $10.00 \%$ \\
Total & 40 & $100.00 \%$ \\
\hline
\end{tabular}

Berdasarkan tabel di atas dapat dilihat dari 40 mahasiswa yang diteliti ada 7 orang $17.50 \%$ ) yang memiliki $\mathrm{pH} 5$ sampai
5.6, 29 orang $(72.50 \%)$ yang memiliki $\mathrm{pH} 6$ sampai 6.8 , dan 4 orang $(10.00 \%)$ yang memiliki pH 7 sampai 7.2 .

Tabel 4 Distribusi Frekuensi DMF-T Mahasiswa D-IV Alih Jenjang Jurusan Keperawatan Gigi Poltekes Makassar

\begin{tabular}{ccc}
\hline DMFT & Jumlah Mahasiswa & Persentase (\%) \\
\hline $\mathbf{0}$ & 7 & $17.50 \%$ \\
$\mathbf{1}$ & 2 & $5.00 \%$ \\
$\mathbf{2}$ & 7 & $17.50 \%$ \\
$\mathbf{3}$ & 5 & $12.50 \%$ \\
$\mathbf{4}$ & 8 & $20.00 \%$ \\
$\mathbf{5}$ & 4 & $10.00 \%$ \\
$\mathbf{6}$ & 3 & $7.50 \%$ \\
$\mathbf{7}$ & 2 & $5.00 \%$ \\
$\mathbf{8}$ & 2 & $5.00 \%$ \\
Total & 40 & $100.00 \%$ \\
\hline
\end{tabular}

Berdasarkan tabel di atas dapat dilihat bahwa dari 40 orang mahasiswa yang diteliti ada 7 orang dengan DMF-T 0 atau bebas karies, 2 orang dengan DMF-T 1, 7 orang dengan DMF-T 2, 5 orang dengan DMF-T 3, 8 orang dengan DMF-T 4, 4 orang dengan DMF-T 5, 3 orang dengan DMF-T 6, 2 orang dengan DMF-T 7 dan 8.

Tabel 5 Distribusi Pengaruh Frekuensi Minum Soft Drink terhadap pH saliva Mahasiswa D-IV Alih Jenjang Jurusan Keperawatan Gigi Poltekes Makassar

\begin{tabular}{ccc}
\hline pH & Frekuensi minum dalam satu minggu & Jumlah Mahasiswa \\
\hline $5-5.6$ & $2-6$ kali & 7 \\
$6-6.8$ & $1-3$ kali & 29 \\
$7-7.2$ & 0 kali & 4 \\
& & 40 \\
\hline
\end{tabular}


Berdasarkan tabel di atas dapat dilihat ada 7 orang yang memiliki $\mathrm{pH}$ saliva 5sampai 5.6 dengan frekuensi minum soft drink 2 sampai 6 kali dalam seminggu, 29 orang yang memiliki $\mathrm{pH}$ saliva 6 sampai 6.8 dengan frekuensi minum soft drink 1 sampai 3 kali seminggu, dan 4 orang yang memiliki $\mathrm{pH}$ saliva 7 sampai 7.2 dengan frekuensi minum soft drink 0 kali atau tidak pernah dalam seminggu.

Tabel 6 Distribusi Frekuensi Hubungan DMF-T Terhadap Frekuensi Meminum Soft Drink

\begin{tabular}{c|ccccccc|c}
\hline \multirow{2}{*}{ DMF-T } & \multicolumn{7}{|c}{ Frekuensi Minum soft drink } \\
\cline { 2 - 9 } & $\mathbf{0}$ & $\mathbf{1}$ & $\mathbf{2}$ & $\mathbf{3}$ & $\mathbf{4}$ & $\mathbf{5}$ & $\mathbf{6}$ & $\begin{array}{c}\text { Jumlah } \\
\text { Mahasiswa }\end{array}$ \\
\hline $\mathbf{0}$ & 2 & - & 1 & 3 & - & - & 1 & 7 \\
\hline $\mathbf{1}$ & 1 & 1 & - & - & - & - & - & 2 \\
\hline $\mathbf{2}$ & 1 & 4 & 2 & - & - & - & - & 7 \\
\hline $\mathbf{3}$ & - & 3 & 1 & - & - & 1 & - & 5 \\
\hline $\mathbf{4}$ & - & 4 & - & 3 & 1 & - & - & 8 \\
\hline $\mathbf{5}$ & - & 1 & - & 1 & - & 1 & 1 & 4 \\
\hline $\mathbf{6}$ & - & 1 & 1 & 1 & - & - & - & 3 \\
\hline $\mathbf{7}$ & - & 1 & - & - & - & 1 & - & 2 \\
\hline $\mathbf{8}$ & - & 1 & 1 & - & - & - & - & 2 \\
\hline Total & $\mathbf{4}$ & $\mathbf{1 6}$ & $\mathbf{6}$ & $\mathbf{8}$ & $\mathbf{1}$ & $\mathbf{3}$ & $\mathbf{2}$ & $\mathbf{4 0}$ \\
\hline
\end{tabular}

Dari tabel frekuensi di atas dapat dilihat ada 7 orang yang memiliki DMF-T 0 dinantaranya 2 orang dengan frekuensi minum soft drink 0 kali (tidak pernah) dalam seminggu, 1 orang dengan frekuensi minum soft drink 2 kali dalam seminggu, 3 orang dengan frekuensi minum soft drink 3 kali dalam seminggu dan 1 orang dengan frekuensi minum soft drink 6 kali dalam seminggu. Ada 2 orang yang memiliki DMF-T 1 di antaranya 1 orang dengan frekuensi minum soft drink 0 kali dalam seminggu dan 1 orang dengan frekuensi minum soft drink 1 kali dalam seminggu. Ada 7 orang yang memiliki DMF-T 2 diantaranya 1 orang dengan frekuensi minum soft drink 0 kali dalam seminggu, 4 orang dengan frekuensi minum soft drink 1 kali dalam seminggu dan 2 orang dengan frekuensi minum soft drink 2 kali dalam seminggu. Ada 5 yang memiliki
DMF-T 3 di antaranya 3 orang dengan frekuensi minum soft drink 1 kali dalam seminggu, 1 orang dengan frekuensi mium soft drink 2 kali dalam seminggu dan 1 orang dengan frekuensi minum soft drink 5 kali dalam seminggu. Ada 8 orang yang memiliki DMF-T 4 di antaranya 4 orang dengan frekuensi minum soft drink 1 kali dalam seminggu, 3 orang dengan frekuensi minum soft drink 3 kali dalam seminggu dan 1 orang dengan frekuensi minum soft drink 4 kali dalam seminggu. Ada 4 orang yang memiliki DMF-T 5 diantaranya 1 orang dengan frekuensi minum soft drink 1 kali dalam seminggu, 1 orang dengan frekuensi minum soft drink 3 kali dalam seminggu, 1 orang dengan frekuensi minum soft drink 5 kali dalam seminggu dan 1 orang dengan frekuensi minum soft drink 6 kali dalam seminggu. Ada 3 orang yang memiliki DMF-T 
6 diantaranya 1 orang dengan frekuensi minum soft drink 1 kali dalam seminggu, 1 orang dengan frekuensi minum soft drink 2 kali dalam seminggu dan1 orang dengan frekuensi minum soft drink 3 kali dalam seminggu. Ada 2 orang yang memiliki DMF-T 7 diantaranya 1 orang dengan frekuensi minum soft drink 1 kali dalam seminggu dan 1 orang dengan frekuensi minum soft drink 5 kali dalam seminggu. Ada 2 orang yang memiliki DMF-T 8 diantaranya 1 orang dengan frekuensi minum soft drink 1 kali dalam seminggu dan 1orang lainnya dengan frekuensi minum soft drink 2 kali dalam seminggu.

\section{Tabel 7 Hasil Uji Kolersi Antara Frekuensi Minum Soft Drink Dengan pH Saliva Dan Antara Frekuensi Minum Soft Drink Dengan Angka DMF-T}

\section{Correlations}

\begin{tabular}{|c|c|c|c|c|}
\hline \multicolumn{3}{|c|}{ Frekuensi Minum Soft Drink } & DMF-T & pH Saliva \\
\hline \multirow{3}{*}{ Frekuensi Minum Soft Drink } & Pearson Correlation & 1 & .155 & $-.855^{\star *}$ \\
\hline & \multicolumn{2}{|c|}{ Sig. (2-tailed) } & .341 & .000 \\
\hline & $\mathrm{N}$ & 40 & 40 & 40 \\
\hline \multirow{3}{*}{$\mathrm{pH}$ Saliva } & Pearson Correlation & $-.855^{\star *}$ & .222 & 1 \\
\hline & Sig. (2-tailed) & .000 & .169 & \\
\hline & $\mathrm{N}$ & 40 & 40 & 40 \\
\hline \multirow{3}{*}{ DMF-T } & Pearson Correlation & .155 & 1 & 222 \\
\hline & Sig. (2-tailed) & .341 & & .169 \\
\hline & $\mathrm{N}$ & 40 & 40 & 40 \\
\hline
\end{tabular}

${ }^{* *}$. Correlation is significant at the 0.01 level (2-tailed).

Berdasarkan table di atas diperoleh korelasi antara Frekuensi Minum soft drink dengan $\mathrm{pH}$ Saliva. Nilai korelasi yang terbentuk adalah 0.855 dengan nilai Sign $0.000<0.05$ menjelaskan bahwa korelasi yang berarti atau signifikan. Korelasi negatif menunjukkan hubungan yang berlawanan antara kedua nilai, yang berarti jika nilai Frekuensi Minum soft drink naik, maka $\mathrm{pH}$
Saliva akan turun. Sedangkan korelasi antara Frekuensi Minum soft drink dengan DMF-T menunjukkan korelasi 0.222. yang menjelaskan bahwa jika Frekunsi Minum soft drink naik, maka nilai DMF-T akan ikut naik, begitupun sebaliknya. Namun, nilai Sign menunjukkan korelasi yang tidak berarti atau tidak signfikaan $0.169>0.05$ 
Tabel 8 Hasil Uji Kolerasi Antara Frekuensi Minum Soft Drink Dan pH saliva Terhadap Angka DMF-T

\begin{tabular}{|c|c|c|c|c|}
\hline \multicolumn{3}{|c|}{ Correlations } & \multirow{3}{*}{$\frac{\text { DMF-T }}{1.000}$} & \multirow{3}{*}{$\frac{\mathrm{pH} \text { Saliva }}{.175}$} \\
\hline Control Variables & & & & \\
\hline \multirow{4}{*}{$\begin{array}{l}\text { Frekuensi Minum } \\
\text { Siswa }\end{array}$} & DMF-T & Correlation & & \\
\hline & & Significance (2-tailed) & . & .287 \\
\hline & df & & 0 & 37 \\
\hline & & Correlation & .175 & 1.000 \\
\hline \multirow[t]{2}{*}{ pH Saliva } & & Significance (2-tailed) & .287 & . \\
\hline & & df & 37 & 0 \\
\hline
\end{tabular}

Dari tabel di atas menunjukkan bahwa Korelasi antara Frekuensi Minum soft drink dan $\mathrm{pH}$ Saliva terhadap DMF-T sebesar 0.175 dengan korelasi nilai Sig 0.287>0.05, menjelaskan bahwa korelasi antara Frekuensi Minum soft drink dan $\mathrm{pH}$ Saliva terhadap angka DMF-T tidak signfikan atau tidak berarti.

Dari tabel 5 dapat diperoleh dari 40 mahasiswa D-IV Alih Jenjang Jurusan Keperawatan Gigi Poltekkes Makassar terdapat 7 orang yang memiliki $\mathrm{pH}$ saliva 5 sampai 5.6 dengan frekuensi minum soft drink 2 sampai 6 kali dalam seminggu, 29 orang yang memiliki pH saliva 6 sampai 6.8 dengan frekuensi minum soft drink 1 sampai 3 kali seminggu, dan 4 orang yang memiliki $\mathrm{pH}$ saliva 7 sampai 7.2 dengan frekuensi minum soft drink 0 kali atau tidak pernah dalam seminggu. Hal ini menunjukkan adanya hubungan frekuensi meminum soft drink dengan $\mathrm{pH}$ saliva dimana jika jumlah frekuensi soft drink besar maka $\mathrm{pH}$ saliva menurun (asam). Dengan melalui uji kolerasi maka data yang signifikan dengan kolerasi yaitu 0,855. Penurunan $\mathrm{pH}$ saliva ini dikarenakan minuman ringan bersifat asam dan memiliki $\mathrm{pH} 3.0$ atau lebih rendah yang dapat menyebabkan demineralisasi pada jaringan keras gigi. (Aritonang, 2014)
Pada tabel 6 dan 7 bahwa frekuansi minum soft drink tidak berhubungan dengan angka DMF-T karena hasil uji kolerasi yang diperoleh adalah nilai kolerasi 0.2222 yang menjelaskan bahwa jika Frekunsi Minum soft drink naik, maka nilai DMF-T akan ikut naik, begitupun sebaliknya. Namun, nilai Sign menunjukkan korelasi yang tidak berarti atau tidak signfikaan $0.169>0.05$. Hal itu terjadi karena beberapa mahasiswa memiliki angka DMF-T tinggi dengan frekuensi minum soft drink yang rendah begitupun sebaliknya beberapa mahasiswa memiliki angka DMF-T rendah bahkan tidak ada sama sekali dengan frekuensi minum soft drink yang tinggi

Dari hasil penelitian ini dapat pula diketahui bahwa nilai $\mathrm{pH}$ saliva dan angka DMF-T inD-IVidu berbeda dikarenakan kondisi dari tiap rongga mulut masing-masing. Kondisi yang berbeda ini disebabkan oleh banyak faktor salah satunya adalah kebiasaan setelah mengkonsumsi soft drink dan pengetahuan tentang kesehtan gigi tiap orang berbeda.

Hasil penelitian ini kurang sejalan dengan hasil penelitian yang dilakukan oleh Intan Aritonang pada tahun 2014 tentang hubungan frekuensi minum soft drink (bersoda) terhadap $\mathrm{pH}$ saliva dan angka DMFT Pada Siswa A/I Kelas XI Ipa Man 2 
Model Jalan Willem Iskandar NO. 7A Kec. Medan Tembung dari hasil penelitian tersebut adalah semakin banyak frekuensi minum soft drink maka semakin rendah $\mathrm{pH}$ saliva dan semakin tinggi frekuensi minum soft drink maka semakin tinggi angka DMF-T.

Perbedaan hasil ini bisa terjadi dikarenakan perbedaan usia sampel, kondisi rongga mulut, kebiasaan setelah mengkonsumsi soft drink dan tingkat pengetahuan tentang kesehatan gigi yang berbeda. Hal ini sesuai dengan hasil penelitian dari Ramadhan, Dkk tentang Hubungan Tingkat Pengetahuan Kesehatan Gigi Dan Mulut Terhadap Angka Karies Gigi di SMPN 1 Marabahan yang menyatakan bahwa terdapat hubungan tingkat pengetahuan kesehatan gigi dan mulut terhadap angka karies gigi. Rendahnya pengetahuan mengenai kesehatan merupakan faktor predisposisi dari perilaku kesehatan yang mengarah kepada timbulnya penyakit. Pengetahuan ini erat pula kaitannya dengan sikap seseorang tentang penyakit dan upaya pencegahannya. Semakin tinggi tingkatan sekolah anak maka peran pengetahuan akan semakin terlihat.

\section{SIMPULAN DAN SARAN}

Hasil uji kolerasi diperoleh nilai korelasi yang terbentuk adalah 0.855 dengan nilai Sign $0.000<0.05$ menunjukkan ada hubungan antara frekuensi minum soft drink dengan $\mathrm{pH}$ saliva dimana ketika frekuensi minum soft drink meningkat maka nilai $\mathrm{pH}$ saliva akan menurun. Hasil uji kolerasi diperoleh nilai kolerasi 0.222 dengan nilai Sign $0.169>0.05$ menunjukkan korelasi yang tidak berarti atau tidak signfikaan (tidak ada hubungan) antara frekuensi minum soft drink dengan angka DMF-T diamana ketika frekuensi minum soft drink meingkat hal itu tidak berhubungan dengan anka DMF-T. Hasil uji kolerasi diperoleh nilai kolerasi 0.175 dengan korelasi nilai Sig $0.285>0.05$, menjelaskan bahwa korelasi antara Frekuensi Minum soft drink dan $\mathrm{pH}$ Saliva terhadap angka DMF-T tidak signfikan atau tidak berarti dimana ketika nilai frekuensi minum soft drink meningkat dan $\mathrm{pH}$ saliva menurun tidak berhubungan dengan angka DMF-T.

Kepada mahasiswa/i yang frekuensi minum soft drinknya tinggi diharapkan dapat mengurangi meminum soft drink (bersoda) untuk mencengah penurunan $\mathrm{pH}$ saliva menjadi lebih rendah. Kepada mahasiswa/i yang melakukan pencegahan karies yang maksimal seperti melakukan pit dan fissure sealant pada gigi molar agar dipertahankan dan bagi yang tidak melakukan diharapkan melakukan pemeriksaan gigi dan mulut secara berkala.

\section{DAFTAR PUSTAKA}

Amerongen A. Van Nieuw.1988. Ludah dan kelenjar ludah: arti bagi kesehatan gigi. Yogyakarta: Gadjah Mada University Press. Hal: 18-19.

Andrew Armand. 2010. Perubahan $\mathrm{pH}$ saliva setelah mengkonsumsi minuman isotonic dan minuman produk olahan susu pada mahasiswa FKG USU. Skripsi. Fakultas Kedokteran Gigi Universitas Sumatera Utara Medan.

Aritonang Intan. 2014." Hubungan frekuensi minum soft drink terhadap $\mathrm{pH}$ saliva dan angka DMFT pada siswa $\mathrm{A} / \mathrm{I}$ kelas $\mathrm{XI}$ ipa MAN 2 MODEL jalan

Erlinda. 2015. Pengaruh pewarna sintetis minuman ringan terhadap kadar kreatinin darah mencit (Mus musculus). Skripsi. Institusi Pertanian Bogor.

Iskandar Williem No.7A Kec.Medan TembungTahun 2014" dalam: Jurnal ilmiah panmed. Jurusan Keperawatan Gigi Poltekkes Kemenkes Medan.

Jannah.2016. Perbedaan pengaruh 
pendidikan kesehatan tentang karies gigi melalui media buku cerita bergambar dan leaflet terhadap pengetahuan, sikap, dan perilaku anak sekolah dasar di kabupaten malang. Skripsi thesis, Universitas Muhammadiyah Surakarta.

Linardi Alicia Nadia. 2014. Perbedaan pH saliva antara pengguna pasta gigi yang mengandung baking soda dan pengguna pasta gigi yang mengandung fluor. Skripsi. Fakultas Kedokteran Gigi Universitas Hasanuddin Makassar.

Nabila Anisa, Siti Sulastri dan Almujadi. 2016. "Pengaruh sebelum dan sesudah minum minuman bersoda terhadap $(\mathrm{pH})$ saliva pada mahasiswa asrama jurusan keperawatan gigi" dalam : jurnal gigi dan mulut vol.1, Jurusan keperawatan gigi poltekkes kemenkes yogyakarta.

Prasetyo Edhie Arif. 2005. "Keasaman minuman ringan menurunkan kekerasan permukaan gigi" dalam:
Dental Jurnal (majalah kedoteran gigi). Fakultas Kedokteran Gigi Universitas Airlangga.

Rahmawati Ida, Fahmi Said dan Sri Hidayati. 2015. "Perbedaan pH saliva antar a sebelum dan sesudah mengkonsumsi minuman ringa" dalam: jurnal skala kesehatan volume 6 No. 1

Ramadhan Azhary, Cholil dan Bayu Indra Sukmana. 2016" Hubungan Tingkat Pengetahuan Kesehatan Gigi Dan Mulut Terhadap Angka Karies Gigi Di Smpn 1 Marabahan" dalam: jurnal kedokteran gigi Vol I. No 2.

Reksi Muhammad Hasanu. 2016. "Pengaruh Minuman Ringan Terhadap Saliva". Diambil dari: http://reksihasanu99.blogspot.com / [diakses: 27 september 2018]

Suraidah. 2005. Perbedaan pengaruh minuman ringan yang mengandung asam sitrat dengan asam bikarbonat terhadap saliva. Skripsi. Fakultas Kedokteran Gigi Universitas Hasanuddin. 